\title{
Primary ridge augmentation with collagenated xenogenic block bone substitute in combination with collagen membrane and rhBMP-2: a pilot histological investigation
}

Benic, Goran I ; Joo, Myung-Jae ; Yoon, So-Ra ; Cha, Jae-Kook ; Jung, Ui-Won

DOI: https://doi.org/10.1111/clr.13024

Posted at the Zurich Open Repository and Archive, University of Zurich

ZORA URL: https://doi.org/10.5167/uzh-139610

Journal Article

Accepted Version

Originally published at:

Benic, Goran I; Joo, Myung-Jae; Yoon, So-Ra; Cha, Jae-Kook; Jung, Ui-Won (2017). Primary ridge augmentation with collagenated xenogenic block bone substitute in combination with collagen membrane and rhBMP-2: a pilot histological investigation. Clinical Oral Implants Research, 28(12):1543-1552.

DOI: https://doi.org/10.1111/clr.13024 


\section{Primary ridge augmentation with collagenated xenogenic block bone substitute in combination with collagen membrane and rhBMP-2: a pilot histologic investigation}

\section{Goran I. Benic*¹, Myung-Jae Joo*², So-Ra Yoon ${ }^{2}$, Jae-Kook Cha ${ }^{2}$, Ui-Won Jung ${ }^{2}$}

*: Equal contribution to the investigation

1: Clinic of Fixed and Removable Prosthodontics and Dental Material Science, Center of Dental Medicine, University of Zurich, Switzerland

2: Department of Periodontology, Research Institute for Periodontal Regeneration, Yonsei University College of Dentistry, Seoul, Republic of Korea

Key words: animal study, bone regeneration, bone augmentation, GBR, ridge augmentation, dental implants, bone substitute, bone graft, block, membrane, bone morphogenetic protein 2, histology

Running title: Xenograft block and BMP-2 for primary ridge augmentation

Corresponding author:

Ui-Won Jung, PhD. DDS.

Department of Periodontology, Yonsei University, College of Dentistry

50-1 Yonseiro Seodaemungu, Seoul, 120-752, South Korea

Phone: +82 2 2228-3185

Fax: +8223920398

e-mail: drjew@yuhs.ac 


\section{Abstract}

Aim: The aim of the present pilot study was to test whether a porcine collagenated bone substitute block (PCBB) and collagen membrane (CM) loaded with bone morphogenetic protein-2 (BMP-2) used for horizontal ridge augmentation differ from PCBB and $\mathrm{CM}$ without BMP-2 regarding the osseointegration of the grafting material and the maintenance of the ridge contour.

Material \& Methods: Two semi-saddle bone defects were created in each side of the mandible of 6 dogs. The defects were randomly allocated to receive one of the following treatments: bone augmentation using (1) PCBB, (2) PCBB loaded with BMP-2 (PCBBBMP2), (3) $\mathrm{PCBB}+\mathrm{CM}$, and (4) $\mathrm{PCBB}+\mathrm{CM}$ loaded with BMP-2 (PCBB+CM-BMP2). After 12 weeks, one titanium implant was inserted into every defect. After 8 weeks, one central histological section of each site was prepared. Histomorphometrical assessments were performed evaluating the augmented area (AA), the area of new bone (NB) (primary outcome), residual bone substitute (BS), and non-mineralized tissue (NMT) within AA in $\mathrm{mm}^{2}$. In addition, the most coronal and the most buccal localizations of new bone and residual bone substitute, and the most coronal bone-to-implant-contact were measured in $\mathrm{mm}$.

Results: Clinically, all PCBB were firmly integrated and permitted implant placement. All the implants osseointegrated and exhibited complete hard tissue coverage of the buccal surface. Bone ingrowth always reached the central portions of PCBB. AA measured $10.4 \pm 4.2$ $\mathrm{mm}^{2}$ for PCBB, $11.8 \pm 2.8 \mathrm{~mm}^{2}$ for PCBB-BMP2, $9.8 \pm 2.9 \mathrm{~mm}^{2}$ for PCBB $+\mathrm{CM}$, and $8.5 \pm 2.2$ $\mathrm{mm}^{2}$ for PCBB+CM-BMP2. Only the difference between PCBB-BMP2 and PCBB+CM-BMP2 was statistically significant $(P=0.031)$. NB reached $2.3 \pm 1.3 \mathrm{~mm}^{2}$ for $P C B B, 2.0 \pm 0.5 \mathrm{~mm}^{2}$ for PCBB-BMP2, $2.7 \pm 1.2 \mathrm{~mm}^{2}$ for $\mathrm{PCBB}+\mathrm{CM}$, and $1.8 \pm 0.7 \mathrm{~mm}^{2}$ for PCBB+CM-BMP2. There were no statistically significant differences regarding NB, the most coronal and the most buccal localizations of new bone, residual bone substitute, and bone-to-implant-contact $(P>0.05)$.

Conclusions: The addition of BMP-2 to PCBB or CM used for horizontal ridge augmentation did not render a statistically significant improvement in the maintenance of the augmented ridge contour and the new bone formation. PCBB with and without CM showed pronounced bone ingrowth and capacity to maintain the augmented ridge contour. In all the regions previously augmented with $\mathrm{PCBB}$, the implants successfully integrated and presented with complete hard tissue coverage. 


\section{Introduction}

A prerequisite for long-term survival of dental implants is a sufficient amount of bone at the implant recipient site to allow osseointegration of the endosseous implant surface. Guided bone regeneration (GBR) with particulate xenogenic bone substitutes in combination with resorbable collagen membranes (CM) is currently the most widely used and welldocumented method used to augment bone in localized alveolar defects simultaneously to implant placement (Benic \& Hammerle 2014; Chiapasco \& Zaniboni 2009; Jensen \& Terheyden 2009; Lee et al. 2015). In jaw regions with reduced ridge width precluding the primary stability of the implant in the prosthetically correct position, the staged approach for bone regeneration and implant placement is chosen. Autogenous bone blocks, alone, or in combination with particulate bone substitute and/or CM, are the most reliable and successful procedures for staged augmentations of large bone defects prior to implant placement (Jensen \& Terheyden 2009; Klein \& Al-Nawas 2011). However, morbidity and risk of complications related to the donor site, limited graft availability and unpredictable graft resorption are major limitations related to the use of autogenous bone (Cordaro et al. 2002; Cordaro et al. 2011; Johansson et al. 2001; Nkenke et al. 2001; von Arx et al. 2005; Widmark et al. 1997; Zeltner et al. 2016).

To overcome these shortcomings, bone substitute blocks were developed as replacements to autogenous bone blocks for primary ridge augmentations procedures. Among different types of bone substitute blocks the research initially focused on the xenogenic materials. Several preclinical studies investigated the use of blocks of deproteinized bovine bone mineral (DBBM) for lateral (Araujo et al. 2002; Benic et al. 2016; De Santis et al. 2012; Schwarz et al. 2008) and vertical bone augmentation procedures (Schmitt et al. 2013; Simion et al. 2006). In other animal studies an equine-derived block of bone mineral containing collagen remnants was used for ridge augmentations of large defects (Benic et al. 2016; Fontana et al. 2008; Schwarz et al. 2010; Simion et al. 2009). These studies found that the block bone substitutes under investigation present scarce osteoconductive properties. In general, DBBM and equine blocks revealed poor bone ingrowth with little newly formed bone in the peripheral parts of the graft. The block materials were mostly embedded in fibrous tissue.

Research has been directed toward growth factors, aiming at resolving the long treatment time and the limited predictability of bone regeneration at extensive bone defects (Reddi et al. 1987; Urist 1965). Various growth factors, including bone morphogenetic proteins (BMP), growth and differentiation factors (GDF), platelet-derived growth factor (PDGF), vascular endothelial growth factor (VEGF), insulin-like growth factor, peptides of the parathyroid hormone $(\mathrm{PTH})$ and enamel matrix derivative, have been evaluated for bone 
regeneration procedures. A systematic review assessed the preclinical and human studies regarding clinical, histological and radiographic outcome of the use of growth factors for localized alveolar ridge augmentation (Jung et al. 2008). Different levels and quantity of evidence were available for the growth factors evaluated, revealing that BMP-2, BMP-7, GDF- 5, PDGF and PTH may stimulate local bone augmentation to various degrees.

Although growth factors and xenograft blocks are available since several years, there is no clinical and scarce preclinical evidence for the use of growth factors in combination with xenogenic bone substitute blocks. Previous animal studies found pronounced osseointegration of the grafting material when DBBM blocks or equine blocks were loaded with PDGF, BMP-2 or GDF-5 (Schwarz et al. 2008; Simion et al. 2009; Simion et al. 2006). In contrast, in another investigation the osseointegration of DBBM blocks did not improve with the additional use of BMP-2 or VEGF ( $\underline{\text { Schmitt et al. 2013). }}$.

In the majority of the previous studies combining GBR with the application of growth factors, either a bone substitute or a resorbable collagen sponge were used as growth factor carriers. A graft-covering barrier membrane made of collagen can be considered an optional carrier of growth factors, since a membrane loaded with osteoinductive proteins might enhance the osteogenic potential of the periosteum in the mucoperiosteal flap. It was reported that the periosteum is highly osteogenic and rich in the mesenchymal cells that can differentiate into osteoblastic cells (Cho et al. 2011; Hayashi et al. 2008; Zhu et al. 2006). Moreover, preclinical studies documented that collagen membrane can allow early transmembranous anastomosis between the mucoperiosteal flap and the tissue below the membrane (Schwarz et al. 2009; Schwarz et al. 2006). In a previous preclinical study, CM was compared to collagenated DBBM as carrier for BMP-2 in GBR of horizontal defects (Chang et al. 2015). In this study BMP-2 loaded DBBM was covered with CM and compared with DBBM covered with BMP-2 loaded CM. The study found no differences in terms of new bone formation, and concluded that loading of CM with BMP-2 might represent a viable option for enhancing bone healing in onlay bone augmentations.

Therefore, the aim of the present pilot study was to test whether a porcine-derived collagenated bone substitute block (PCBB) and CM loaded with BMP-2 used for horizontal ridge augmentation perform differently from PCBB and CM without BMP-2 with regard to the osseointegration of the grafting material and the maintenance of the ridge contour. 


\section{Materials and methods}

This article was written in accordance with the ARRIVE guidelines (Kilkenny et al. 2010). Prior to the beginning of the study, the protocol was approved by the Institutional Animal Care and Use Committee, Yonsei Medical Center, Seoul, Korea (approval no. 20130317). The experimental part of this study was conducted from December 2013 to April 2014.

\section{Animals}

Six male adult beagle dogs (age $12 \pm 3$ months, mean weight $8 \mathrm{~kg}$ ) (Gukje, Pocheon, Korea) were included in this study. All animals presented a fully erupted healthy permanent dentition. The dogs were subjected to surgeries and housed at the Department of Laboratory Animal Resources in Yonsei Biomedical Research Institute in Seoul of Korea. The dogs were monitored daily during the entire study period by an accredited veterinarian in the laboratory of animal sciences. The animals housed in separate cages were allowed to move freely under standard laboratory conditions at an average temperature of $21^{\circ} \mathrm{C}$ and relative humidity of $35 \%$ to $65 \%$. During the study period, the animals were fed with canned soft dog food and water ad libitum. The trial began after a 4-week long adaption period for the animals.

\section{Materials for bone augmentation}

The following materials for bone augmentation were used in this study.

Block: porcine-derived collagenated bone substitute block (PCBB) (Collaoss ${ }^{\circledR}$, Bioland, Chungwon, Korea); dimensions $8 \mathrm{~mm}$ (length) x $5 \mathrm{~mm}$ (width) x $4 \mathrm{~mm}$ (height); rigidtype bone substitute comprising $90-98 \%$ porcine bone and $2-10 \%$ cross-linked collagen. The pore size and the porosity were analyzed by a mercury intrusion porosimeter (AutoPore IV 9500, Micromeritics Co. Ltd., Norcross, GA, USA). The average porosity of PCBB measured $76.98 \%$. The specific surface area amounted to $6.044 \mathrm{~m}^{2} / \mathrm{g}$ as assessed by nitrogen adsorption-desorption methodology (supplement Fig. 1). For the preparation of PCBB, cancellous-cortical porcine bone was deproteinized in $15 \% \mathrm{NaOH}$ for 3 hours. The bone was sliced at a thickness of $5-10 \mathrm{~cm}$ and placed in boiling water at $100^{\circ} \mathrm{C}$ for 72 hours.

Subsequently, the bone was heated at $600^{\circ} \mathrm{C}$ for 10 hours to remove any protein and lipid. Processed bone blocks were placed in an aqueous dispersion of collagen. This mixture was poured into an aluminum mold and frozen at $-40^{\circ} \mathrm{C}$ for 12 hours. The samples were then dehydrated for 24 hours under vacuum. The dehydration treatment was performed by placing the freeze-dried mixture in a vacuum oven (OV-02, JEIO TECH, Seoul, Korea) under a pressure of $1 \mathrm{mmHg}$ to cross-link the collagen. The temperature of the samples returned to room temperature before removing the vacuum. 
Collagen membrane (CM): porcine cross-linked collagen membrane (Ossguide ${ }^{\circledR}$; Bioland, Chungwon, Korea); dimensions $12.5 \mathrm{~mm} \times 12.5 \mathrm{~mm}$; type I collagen derived from porcine pericardium. After decellularization and removal of DNA, the collagen matrix was placed into a mold and freeze-dried. The cross-linking process was carried out in the same manner as for PCBB.

rhBMP-2 (BMP2): 2 mg of rhBMP-2 (Cowellmedi, Busan, Korea) was mixed with 1.34 $\mathrm{ml}$ of sterile water and diluted with $2.68 \mathrm{ml}$ of buffer to produce a stock solution of rhBMP-2 at a concentration of $0.5 \mathrm{mg} / \mathrm{ml}$.

\section{Study design and randomization}

This investigation was designed as a randomized controlled trial with intra-subject control for the comparison of 4 treatment procedures. To avoid the local effect of BMP-2 on the sites without BMP-2, the sites with BMP-2 were allocated on one side of the mandible and the sites without BMP-2 on the contralateral side. The site allocations (left vs. right, anterior vs. posterior) were randomly determined by flipping a coin.

The study was performed in 2 surgical phases including (i) tooth extraction and bone augmentation of acute-type defects (four defects per animal) and (ii) implant placement (one implant per defect).

At the first surgical session, the bone defects were randomly allocated to receive one of the following treatment modalities:

- Block: PCBB alone

- Block+CM: PCBB + CM

- Block-BMP2: PCBB loaded with rhBMP-2 $(0.5 \mathrm{mg} / \mathrm{ml}, 0.2 \mathrm{ml})$

- Block+CM-BMP2: PCBB + CM loaded with rhBMP-2 $(0.5 \mathrm{mg} / \mathrm{ml}, 0.2 \mathrm{ml})$

\section{Surgical procedures}

The investigators participating in the study were experienced in implant placement and bone regeneration procedures. Plaque control program was initiated one week before the surgical procedure. All surgical procedures were performed under general anesthesia. The animals were premedicated with ketorolac trometamine $(0.5 \mathrm{mg} / \mathrm{kg} / \mathrm{i} . \mathrm{v}$. Keromin; Hana Pharmaceutical, Hwasung, Korea), enroflaxacin ( $5 \mathrm{mg} / \mathrm{kg} / \mathrm{i} . v$. and i.m. Baytril; Bayer Korea, Ansan, Korea) and cimetidine (5-10mg/kg/i.v.Cimetidine; Taiguk Pharmaceutical, Hwasung, Korea). General anesthesia was inducted by xylazine ( $2 \mathrm{mg} / \mathrm{kg} / \mathrm{i} . v$. Rompun; Bayer Korea, Seoul, Korea) and ketamine hydrochloride (10 mg/kg/i.v. Ketalar; Yuhan, Seoul, Korea), and maintained by inhalation of an $\mathrm{O}_{2}$ and $1-2 \%$ isoflurane mixture (Forane; Choongwae Pharmaceutical, Seoul, Korea). A local anesthesia composed of $2 \%$ lidocaine with 1: 80 '000 
epinephrine (Kwangmyung Pharmaceutical, Seoul, Korea) was used to reduce peri-operative pain and bleeding. During anesthesia, the dogs were monitored by a veterinarian by means of electrocardiography, capnography, pulsioxymetry, and blood pressure measurements. Postoperatively, antibiotics (amoxicillin 13 mg/kg/p.o. Moxicle; Boryung Pharmaceutical, Ansan, Korea) were administrated for 7 days. During the first two postoperative weeks, the oral mucosa and teeth were disinfected three times a week by irrigation of a $0.12 \%$ chlorhexidine solution (Hexamedine; Bukwang Pharmaceutical, Seoul, Korea).

Surgery 1 (tooth extraction, defect preparation and bone augmentation)

The mandibular third and fourth premolars were bilaterally sectioned by using fissure burs and extracted with elevators and forceps. Buccal and lingual mucoperiosteal flaps were elevated and two semi-saddle-type bone defects were prepared on each side of the mandible by removing the buccal wall of the alveoloar ridge. The box-shaped bone defects measured $8 \mathrm{~mm}$ mesio-distally, $4 \mathrm{~mm}$ apico-coronally, and $5 \mathrm{~mm}$ bucco-orally (Fig. 1a).

One drilling with $2.2 \mathrm{~mm}$-diameter was performed in each defect, in the site of the prospective implant placement. The center of the drilling was placed, mesio-distally, in the middle of the bone defect and, bucco-orally, along the lingual bone wall of the defect. Guide pins were inserted in the drill holes, and a pick-up impression was taken using light and heavy body silicone material (Exafine, GC Dental Products Corp, Japan) (Fig. 1b and 1c).

PCBB for the treatment modalities Block and Block+CM was hydrated with sterile $0.9 \%$ saline. For each of the sites Block-BMP2 and Block+CM-BMP2, $0.2 \mathrm{ml}$ of $0.5 \mathrm{mg} / \mathrm{ml}$ rhBMP-2 solution were withdrawn by using a sterile 1-ml syringe and uniformly dispensed over the entire surface of PCBB and CM on a sterile dish. Following a 15-min loading time at room temperature, the rhBMP-2-loaded PCBB was applied to the assigned experimental site in the Block-BMP2 group, and the rhBMP-2-loaded CM was applied on PCBB in the Block+CM-BMP2 group. At the sites Block+CM and Block+CM-BMP2, CM was applied to cover the bone substitute and overlap the walls of the defect (Fig. 1d). No screws or pins were used for stabilization of blocks and membranes. The mucoperiosteal flaps were closed with resorbable sutures (Monosyn ${ }^{\circledR} 4-0$; B Braun, Tuttlingen, Germany). The sutures were removed after 10 days and 12 weeks of healing were allowed.

\section{Surgery 2 (guided implant placement)}

Before the implant surgery, a cast was poured from the pick-up impression taken at the previous surgery. The model was scanned using an optical scanner (Trios, 3Shape, Copenhagen, Denmark) and the data were used to digitally design (OnDemand3D, Cybermed, Seoul, Korea) a tooth-supported surgical guide for the placement of implants along the original interface between the native bone and PCBB. A guide for static implant placement was produced by using a 3D printer (3Dent, EnvisionTEC, Germany). 
After 12 weeks of healing, a mid-crestal incision was performed and mucoperiosteal flaps were elevated. The condition of alveolar ridge was examined to assess whether the bone graft was integrated to allow implant placement. The surgical guide was applied onto the remaining dentition and used for static guided implant placement (Fig. 2a and 2b). Two cylindrical titanium bone level implants with acid-etched and sandblasted surface (NR line, Dentium, Seoul, Korea) were installed in each side of the mandible with implant shoulders at the level of alveolar bone crest. All the implants exhibited a diameter of $3.6 \mathrm{~mm}$ and a length of $9 \mathrm{~mm}$. Cover screws were inserted and all implants were submerged for 8 weeks.

\section{Retrieval of specimens}

Eight weeks after implant placement, the animals were sedated with inhalation of $5 \%$ isoflurane (Forane; Choongwae Pharmaceutical, Seoul, Korea) and subsequently sacrificed with an overdose of potassium chloride $(1.5 \mathrm{mg} / \mathrm{kg} / \mathrm{i} . \mathrm{v}$. Potassium Chloride-40 Injection Daihan; Daihan Pharmaceutical, Seoul, Korea). The mandibles were block-resected including the surrounding soft tissues.

\section{Histological preparation}

Fixation of the specimens was performed in buffered $4 \%$ neutral formaldehyde solution. The specimens were dehydrated using ethanol solutions of increasing concentrations and subsequently embedded in a composite resin (Technovit 7200 VLC, Heraeus Kulzer, Hanau, Germany). One bucco-oral section through the central axis of the implant was prepared from each site. The tissue blocks were sectioned using a diamond cutting system (EXAKT 300 CP, EXAKT Apparatebau, Norderstedt, Germany) and the sections were ground and polished to a thickness of 35-45 $\mu \mathrm{m}$ (KULZER EXAKT 400CS, EXAKT Apparatebau, Norderstedt, Germany). The sections were stained with hematoxylin and eosin (Fig. 3).

\section{Histomorphometrical analysis}

Histomorphometrical analysis was performed by one investigator that was unaware of the specific experimental conditions. A digital color camera (Leica DFC 450, Leica Mikrosysteme, Wetzlar, Germany) connected to a light microscope (Microscope Leica DM6000, Leica Mikrosysteme) was used for image capturing. For histomorphometrical analysis, digital images were evaluated using an image analysis software (Leica Application Suite V4.3, Leica Mikrosysteme).

For each section, the following variables were assessed:

- the augmented area $(\mathrm{AA})\left(\mathrm{mm}^{2}\right)$ within the former bone defect at the buccal aspect (Fig. 4) 
- the area of new mineralized bone (NB) $\left(\mathrm{mm}^{2}\right)$ (primary outcome variable), residual bone substitute (BS) $\left(\mathrm{mm}^{2}\right)$, and non-mineralized tissue (NMT) $\left(\mathrm{mm}^{2}\right)$ within AA (Fig. 4)

- the apico-coronal distance $(\mathrm{mm})$ between the apical margin of the former bone defect (DEF) and the most coronal level of bone in contact with the implant (DEFfBIC) (Fig. 5)

- the apico-coronal distances $(\mathrm{mm})$ between DEF and the most coronal level of new bone (DEF-NB), and between DEF and the most coronal level of bone substitute (DEF-BS) (Fig. 5)

- the bucco-oral distances $(\mathrm{mm})$ between the buccal implant surface $(\mathrm{I})$ and the most buccal aspect of new bone (I-NB), and between I and the most buccal aspect of bone substitute (I-BS) (Fig. 5).

\section{Statistical analysis}

The animal was chosen as the unit for the statistical analysis. The data were reported by using means, standard deviations (SD), medians, and interquartile ranges (IQR) (SPSS software; SPSS Inc., Chicago, IL, USA). The Wilcoxon signed rank test was applied to detect differences between the treatments ( $R$ software; $R$ Foundation, Vienna, Austria). The results of tests with $\mathrm{P}$-values $\leq 0.05$ were considered statistically significant. Due to the exploratory nature of this study, no sample size calculation and no correction for multiple testing were performed. 


\section{Results}

\section{Clinical findings}

Intraoperatively, PCBB permitted a press-fit mechanical anchorage within the boxshaped defects without fracturing. All animals remained healthy during the entire study period. No systemic or local adverse events were observed. At reentry, PCBB was firmly integrated with the adjacent native bone and all the sites allowed implant placement along the interface between PCBB and native bone.

\section{Histological findings}

A total of 6 Block, 6 Block-BMP2, 6 Block+CM, and 6 Block+CM-BMP2 sites were available for the histological and the histomorphometrical analysis. All the implants were osseointegrated and presented with complete hard tissue coverage of the buccal surface intended for osseointegration. Bone ingrowth always reached the central portions of the blocks. New bone within the blocks mostly reached more buccally in comparison to the buccal contour of the native bone apical to PCBB. In the majority of the specimens, PCBB trabeculae did not reveal fractures or signs of resorption.

\section{Histomorphometrical findings}

Augmented area (AA) amounted to $10.4 \pm 4.2 \mathrm{~mm}^{2}$ (SD) for Block, $11.8 \pm 2.8 \mathrm{~mm}^{2}$ (SD) for Block-BMP2, $9.8 \pm 2.9 \mathrm{~mm}^{2}$ (SD) for Block+CM, and $8.5 \pm 2.2 \mathrm{~mm}^{2}$ (SD) for Block+CM-BMP2 (Table 1, Fig. 6). Only the difference between Block-BMP2 and Block+CMBMP2 was statistically significant $(P=0.031)$.

New mineralized bone (NB) measured $2.3 \pm 1.3 \mathrm{~mm}^{2}(\mathrm{SD})$ for Block, $2.0 \pm 0.5 \mathrm{~mm}^{2}$ (SD) for Block-BMP2, $2.7 \pm 1.2 \mathrm{~mm}^{2}$ (SD) for Block+CM, and $1.8 \pm 0.7 \mathrm{~mm}^{2}$ (SD) for Block+CM-BMP2 (Table 1, Fig. 6). There were no statistically significant differences between the treatment modalities $(P>0.05)$ (Table 1, Fig. 6).

Residual bone substitute (BS) reached $3.7 \pm 1.0 \mathrm{~mm}^{2}(\mathrm{SD})$ for Block, $6.1 \pm 2.2 \mathrm{~mm}^{2}$ (SD) for Block-BMP2, $3.4 \pm 1.0 \mathrm{~mm}^{2}$ (SD) for Block+CM, and $3.4 \pm 1.2 \mathrm{~mm}^{2}$ (SD) for Block+CM-BMP2 (Table 1, Fig. 6). Only the difference between Block-BMP2 and Block+CM was statistically significant $(P=0.031)$.

With regard to the distance between the most coronal level of bone in contact with the implant and the apical margin of the former bone defect (DEF-fBIC), the values amounted to $3.0 \pm 0.6 \mathrm{~mm}^{2}$ (SD) for Block, to $2.7 \pm 0.9 \mathrm{~mm}^{2}(\mathrm{SD})$ for Block-BMP2, to $3.0 \pm$ $0.9 \mathrm{~mm}^{2}(\mathrm{SD})$ for Block+CM, and to $2.3 \pm 0.9 \mathrm{~mm}^{2}$ (SD) for Block+CM-BMP2 (Table 1). The results in DEF-fBIC did not differ significantly between the treatment modalities $(P>0.05)$. 
In terms of the most coronal and the most buccal localization of new bone (DEF-NB and I-NB) and residual bone substitute (DEF-BS and I-BS), there were no differences between the treatment modalities $(P>0.05)$ (Table 1$)$. 


\section{Discussion}

The results of the present study demonstrated that the addition of BMP-2 to PCBB or $\mathrm{CM}$ did not render a statistically significant improvement of their performance for horizontal ridge augmentation prior to implant placement. The treatment modalities did not significantly differ regarding the ridge contour and the new bone formation. PCBB with and without CM showed pronounced bone ingrowth and a capacity to maintain the augmented ridge contour. In all the augmented regions, the hard tissue was adequate to place implants along the former interface between the native bone and the grafting material. All the implants osseointegrated and presented with complete hard tissue coverage of the surface intended for osseointegration.

The biologic activity and release kinetics of BMP-2 from porcine-derived particulated bone substitute was investigated in a previous in-vitro study (Yon et al. 2015). The results showed that an initial burst release of $40.8 \%$ occurred during the first three days. At 21 days, the cumulative release of BMP-2 reached $53.8 \%$ of the originally loaded dosis (Yon et al. 2015). The release kinetics of BMP-2 from various carriers was evaluated in other studies (Draenert et al. 2013, Seeherman et al. 2002, Lee et al. 2016). It was reported that collagen has more BMP-2 loading capacity and an initial burst releasing property compared to hydroxyapatite. The PCBB used in this study comprised porcine-derived block bone substitute with an addition of cross-linked collagen. Therefore, a larger amount of BMP-2 thought to be released from PCBB at initial stage compared to particulate bone mineral alone due to the effect of collagen included. The sustained release profile of PCBB is expected to be similar to that of particulated bone.

There is a high level of preclinical and clinical evidence revealing that BMP-2 may stimulate bone regeneration and supporting the use of BMP-2 for ridge preservation, sinus floor elevation and horizontal ridge augmentation (Cha et al. 2014; Jung et al. 2015; Jung et al. 2008; Kim et al. 2015). However, there is no clinical and only scarce preclinical evidence for the use of BMP-2 in combination with xenogenic block bone substitutes for ridge augmentation. A previous preclinical study tested the use of DBBM blocks in combination with BMP-2 or GDF-5 for horizontal ridge augmentation (Schwarz et al. 2008). Chronic-type defects were horizontally augmented with $6 \mathrm{~mm}$-thickness DBBM blocks alone or in combination with BMP-2 or GDF-5. DBBM blocks were loaded either with $2.3 \mathrm{ml}$ of a 0.77 $\mathrm{mg} / \mathrm{ml}$ rhBMP-2 solution (1.77 $\mathrm{mg}$ rhBMP-2 per block) or with a rhGDF-5 solution. The control samples were moistened with sterile saline. All the blocks were screw-retained and covered with a CM. After 3 weeks of healing, there was very little bone ingrowth within DBBM blocks. At 8 weeks, DBBM blocks with BMP-2 and GDF-5 revealed significantly more new bone formation in comparison to DBBM blocks alone. The findings from this study 
contrast with the results of the present trial. The difference in the findings between the studies can be explained by the differences in defect model (present study: acute- versus previous study: chronic-type), bone substitute (PCBB versus DBBM), BMP-2 dose (0.1 $\mathrm{mg} / \mathrm{block}$ versus $1.77 \mathrm{mg} / \mathrm{block}$ ), and time period between bone grafting and sacrifice (20 weeks versus 8 weeks). The findings of the previously described study are in accordance with another study that demonstrated a beneficial effect of BMP-2 combined with DBBM for vertical bone augmentation (Kim et al. 2010). The onlay bone augmentation was performed in the cranial bone of rabbits by using DBBM blocks collagenated with $10 \%$ of porcine collagen (DBBM-collagen). DBBM-collagen was applied (1) alone, (2) covered with CM, or (3) loaded with BMP-2. After 12 weeks, the addition of BMP-2 and the use of barrier membranes rendered more favorable new bone formation in comparison to the control group. In the same study, in addition to DBBM, an allogenic cortico-cancellos bone block was investigated. In all the groups, the allograft block performed better than DBBM in terms of bone ingrowth and volume maintenance. Interestingly, the addition of BMP-2 to the allogenic block did not promote bone ingrowth in comparison to the allograft alone. In another preclinical study, DBBM blocks in combination with BMP-2 and/or VEGF were investigated for vertical bone augmentation in decorticated pig calvariae ( $\underline{\text { Schmitt et al. }}$ 2013). The growth factors mixed with fibrin glue were applied on the blocks. DBBM blocks were screw-retained without membrane coverage. The addition of BMP and/or VEGF did not reveal any promotional effect in the osseointegration. At 1 month, the percentage of bone volume within the total graft volume amounted to approximately $5 \%$. At 2 months, this ratio reached about $10 \%$. New bone was found in the peripheral portions of the block in contact with the native bone. The addition of BMP-2 to synthetic blocks was investigated in a recent preclinical study (Kim et al. 2012). In this study biphasic calcium phosphate blocks with or without collagen matrix were used for vertical bone augmentation in rabbit calvariae. The blocks with and without BMP-2 were screw-retained and no membranes were used. After 8 weeks, the area of new bone was significantly greater in the specimens treated with BMP-2. The findings from the previously described investigations indicate that the effect of the BMP2 depends on the characteristics of the bone substitute. Previous investigation founds that the regenerative potential of growth and differentiation factors is dependent of a carrier material that serves as a delivery system and as a scaffold for cellular ingrowth (Hunt et al. 2001; Sigurdsson et al. 1996).

In the present study, PCBB with or without CM showed a pronounced osseointegration. Bone ingrowth always reached the central portions of the blocks. Moreover, new bone within the blocks mostly reached more buccally in comparison to the contour of the adjacent native ridge. Such a degree of osseointegration is surprising considered the lower osteoconductive capacity of bone substitute blocks in comparison to 
particulate grafting materials (Benic et al. 2016). Indeed, several previous preclinical investigations of xenograft blocks used for ridge augmentation revealed poor bone ingrowth within the blocks that were mostly embedded in fibrous tissue. In these studies DBBM blocks (Araujo et al. 2002; Benic et al. 2016; De Santis et al. 2012; Schmitt et al. 2013; Schwarz et al. 2008; Simion et al. 2006) and equine blocks of bone mineral with remnant collagen (Benic et al. 2016; Fontana et al. 2008; Schwarz et al. 2010; Simion et al. 2009), alone or in combination with $\mathrm{CM}$, were used for horizontal and vertical bone augmentations. In a recent preclinical study, equine bone substitute blocks, DBBM blocks and DBBM granulate in combination with CM were used for the augmentation of large acute-type peri-implant defects (Benic et al. 2016). After 4 months of healing, the blocks showed more favorable results in the ridge contour in comparison to the particulate material. In terms of the surface fraction of bone substitute in contact with new bone, granulate reached higher values compared to the block materials. The difference between DBBM granulate and DBBM block reached statistical significance, indicating a superior osteoconductivity of particulate material in comparison to the block. It was hypothesized that the difference in the rate of bone ingrowth was due to the differences in the macrostructure, with particulate material facilitating ingrowth of blood vessels and new bone. It is important to emphasize that the results in new bone formation of the present study cannot be directly compared with the findings from other investigations of bone substitute blocks. This is due to the differences in multiple factors, such as defect localization, defect type, staging of augmentation, use of membrane, and time period allowed for healing.

In the present trial, at all the sites the width of the augmented ridge allowed implant placement along the interface between the native bone and the grafting material without additional grafting. After 12 weeks, all the implants presented with complete hard tissue coverage of the surface intended for osseointegration. Despite the cross-sectional nature of the assessment in this study, based on the known initial dimensions of the block it can be deduced that PCBB with or without CM showed a capacity to maintain the augmented ridge contour. This finding can be explained by the mechanical stability of the block.

Intraoperatively, the rigid-type block was not prone to fractures, therefore, permitting a pressfit anchorage within the box-shaped defect. Moreover, an intact trabecular network and no fractures of the trabeculae were observed in the histologic specimens. The mechanical properties of PCBB can be explained by the proprietary fabrication process with chemic and thermal deproteinization, followed by an addition of collagen. Previous in-vitro and in-vivo preclinical studies showed the superior performance of bone substitute blocks over particulate materials regarding the contour maintenance after augmentation of non-contained bone defects (Benic et al. 2016; Mir-Mari et al. 2016; Schwarz et al. 2008). 
Another possible explanation for the capacity of PCBB to maintain the augmented contour might by its resistance to biodegradation. In the majority of the histologic samples, PCBB trabeculae did not reveal signs of resorption and the original block form appeared unchanged. It is known that deproteinized xenogenic bone substitutes, such as DBBM, resorb at a very slow rate (Mordenfeld et al. 2010; Shin et al. 2014). In contrast, investigations of an equine-derived bone substitute block with collagen remnants revealed pronounced signs of biomaterial resorption (Benic et al. 2016; Fontana et al. 2008; $\underline{\text { Schwarz }}$ et al. 2010).

In this experiment, a model of an acute-type defect was used for ridge augmentation immediately after tooth extraction. The chronification of bone defects was omitted to standardize the initial defect dimension. This was done aiming at reproducible surgical procedure and histomorphometrical analysis. Consequently, the applied model did not ideally simulate the typical clinical situation of primary ridge augmentation at atrophic jaw regions. The missing sample size calculation and lack of correction for multiple testing represent additional shortcoming of the present pilot trial.

The findings of the present study regarding the osseointegration of PCBB with and without BMP-2 need to be considered with caution due to the small sample size and the variability between the animals. Nevertheless, the clinical and the histologic performance of PCBB used for horizontal ridge augmentation are worth of reporting. In fact, the application of PCBB enabled a successful augmentation of bone defects and osseointegration of all implants in the previously augmented sites. This result is in accordance with a preclinical study and a clinical case series, in which xenogenic blocks were used for horizontal ridge augmentations (De Santis et al. 2012; Hammerle et al. 2008). Based on these observations, it can be concluded that xenograft blocks might represent a viable alternative to autogenous bone blocks for primary ridge augmentation. Further comparative preclinical trials are required to investigate the performance of different bone substitute blocks for ridge augmentation. The influence of bone augmentation with bone substitute blocks on the longterm contour stability of the augmented ridge and the implant success should be examined in clinical studies. 


\section{Conclusions}

Within the limitations of the present study, it can be concluded that for horizontal ridge augmentation with $\mathrm{PCBB}$, alone or in combination with $\mathrm{CM}$, prior to implant placement:

- The addition of BMP-2 to PCBB and CM did not render a statistically significant improvement in the maintenance of the augmented ridge contour and the new bone formation.

- $\quad$ PCBB showed pronounced bone ingrowth and a capacity to maintain the augmented ridge contour.

- All the implants osseointegrated and presented with complete hard tissue coverage of the surface intended for osseointegration. 


\section{Conflict of interest}

The authors declare that they have no conflict of interest related to any product used in the present study. 


\section{Source of funding}

This study was supported by the Basic Science Research Program of the National Research Foundation of Korea (NRF) funded by the Ministry of Education (No.NRF2014R1A1A1A05002953). 


\section{Figures legend}

Fig. 1. (a) Buccal view of the bone defects prior to bone augmentation. (b) Guide pins indicating the prospective implant positions along the lingual bone wall of the defect. (c) Pickup silicone impression with guide pins. (d) Horizontal ridge augmentation with porcine bone substitute block alone (right) and in combination with a collagen membrane (left).

Fig. 2. (a) Surgical template for guided implant placement. (b) Occlusal view after implant placement.

Fig. 3. Histological views: (a) porcine collagenated bone substitute block (PCBB) alone, (b) PCBB loaded with BMP-2, (c) PCBB covered with collagen membrane (CM), (d) PCBB covered with BMP-2 loaded CM.

Fig. 4. Histomorphometrical assessments of (a) the augmented area (green line) and (b) the areas of new mineralized bone (yellow surface), residual bone substitute (red surface), and non-mineralized tissue (green surface) within the augmented area.

Fig. 5. Histomorphometrical assessments of the distances between bone defect and most coronal bone-to-implant contact (DEF- fBIC), new bone (DEF-NB) and bone substitute (DEF-BS), and between implant surface and most buccal new bone (I-NB) and bone substitute (I-BS).

Fig 6. Plots representing (a) the absolute values (in $\mathrm{mm}^{2}$ ) and (b) the relative values (in \%) of new bone (NB), residual bone substitute (BS), and non-mineralized tissue (NMT) within the augmented area (AA) for different treatment modalities.

Supplement Fig 1. Micro computed tomographic images of PCBB exhibiting a porous block form. (Left) Cross-sectional view, (Right) 3-dimensional reconstructed view. 


\section{Table legend}

Table. 1. Results of the (a) histomorphometric analysis; (b) statistical tests for comparisons between the treatment modalities 


\section{References}

Araujo, M. G., Sonohara, M., Hayacibara, R., Cardaropoli, G. \& Lindhe, J. (2002) Lateral ridge augmentation by the use of grafts comprised of autologous bone or a biomaterial. An experiment in the dog. Journal of Clinical Periodontology 29: 11221131.

Benic, G. I. \& Hammerle, C. H. (2014) Horizontal bone augmentation by means of guided bone regeneration. Periodontology 2000 66: 13-40.

Benic, G. I., Thoma, D. S., Munoz, F., Sanz Martin, I., Jung, R. E. \& Hammerle, C. H. (2016) Guided bone regeneration of peri-implant defects with particulated and block xenogenic bone substitutes. Clinical Oral Implants Research 27: 567-576.

Cha, J. K., Lee, J. S., Kim, M. S., Choi, S. H., Cho, K. S. \& Jung, U. W. (2014) Sinus augmentation using bmp-2 in a bovine hydroxyapatite/collagen carrier in dogs. Journal of Clinical Periodontology 41: 86-93.

Chang, Y. Y., Lee, J. S., Kim, M. S., Choi, S. H., Chai, J. K. \& Jung, U. W. (2015) Comparison of collagen membrane and bone substitute as a carrier for rhbmp-2 in lateral onlay graft. Clinical Oral Implants Research 26: e13-19.

Chiapasco, M. \& Zaniboni, M. (2009) Clinical outcomes of gbr procedures to correct peri-implant dehiscences and fenestrations: A systematic review. Clinical Oral Implants Research 20 Suppl 4: 113-123.

Cho, E. H., Park, J. C., Cha, J. K., Kim, Y. T., Jung, U. W., Kim, C. S., Choi, S. H. \& Kim, C. K. (2011) Dimensional change of the healed periosteum on surgically created defects. J Periodontal Implant Sci 41: 176-184.

Cordaro, L., Amade, D. S. \& Cordaro, M. (2002) Clinical results of alveolar ridge augmentation with mandibular block bone grafts in partially edentulous patients prior to implant placement. Clinical Oral Implants Research 13: 103-111.

Cordaro, L., Torsello, F., Miuccio, M. T., di Torresanto, V. M. \& Eliopoulos, D. (2011) Mandibular bone harvesting for alveolar reconstruction and implant placement: Subjective and objective cross-sectional evaluation of donor and recipient site up to 4 years. Clinical Oral Implants Research 22: 1320-1326.

De Santis, E., Lang, N. P., Scala, A., Vigano, P., Salata, L. A. \& Botticelli, D. (2012) Healing outcomes at implants installed in grafted sites: An experimental study in dogs. Clinical Oral Implants Research 23: 340-350.

Draenert, F. G., Nonnenmacher, A. L., Kammerer, P. W., Goldschmitt, J. \& Wagner, W. (2013) Bmp-2 and bfgf release and in vitro effect on human osteoblasts after adsorption to bone grafts and biomaterials. Clinical Oral Implants Research 24: 750757. 
Fontana, F., Rocchietta, I., Dellavia, C., Nevins, M. \& Simion, M. (2008)

Biocompatibility and manageability of a new fixable bone graft for the treatment of localized bone defects: Preliminary study in a dog model. International Journal of Periodontics and Restorative Dentistry 28: 601-607.

Hammerle, C. H., Jung, R. E., Yaman, D. \& Lang, N. P. (2008) Ridge augmentation by applying bioresorbable membranes and deproteinized bovine bone mineral: $\mathrm{A}$ report of twelve consecutive cases. Clinical Oral Implants Research 19: 19-25.

Hayashi, O., Katsube, Y., Hirose, M., Ohgushi, H. \& Ito, H. (2008) Comparison of osteogenic ability of rat mesenchymal stem cells from bone marrow, periosteum, and adipose tissue. Calcified Tissue International 82: 238-247.

Hunt, D. R., Jovanovic, S. A., Wikesjo, U. M., Wozney, J. M. \& Bernard, G. W. (2001) Hyaluronan supports recombinant human bone morphogenetic protein-2 induced bone reconstruction of advanced alveolar ridge defects in dogs. A pilot study. Journal of Periodontology 72: 651-658.

Jensen, S. S. \& Terheyden, H. (2009) Bone augmentation procedures in localized defects in the alveolar ridge: Clinical results with different bone grafts and bonesubstitute materials. International Journal of Oral and Maxillofacial Implants 24 Suppl: 218-236.

Johansson, B., Grepe, A., Wannfors, K. \& Hirsch, J. M. (2001) A clinical study of changes in the volume of bone grafts in the atrophic maxilla. Dento-Maxillo-Facial Radiology 30: 157-161.

Jung, I. H., Lim, H. C., Lee, E. U., Lee, J. S., Jung, U. W. \& Choi, S. H. (2015) Comparative analysis of carrier systems for delivering bone morphogenetic proteins. J Periodontal Implant Sci 45: 136-144.

Jung, R. E., Thoma, D. S. \& Hammerle, C. H. (2008) Assessment of the potential of growth factors for localized alveolar ridge augmentation: A systematic review. Journal of Clinical Periodontology 35: 255-281.

Kilkenny, C., Browne, W. J., Cuthill, I. C., Emerson, M. \& Altman, D. G. (2010) Improving bioscience research reporting: The arrive guidelines for reporting animal research. J Pharmacol Pharmacother 1: 94-99.

Kim, J. S., Cha, J. K., Cho, A. R., Kim, M. S., Lee, J. S., Hong, J. Y., Choi, S. H. \& Jung, U. W. (2015) Acceleration of bone regeneration by bmp-2-loaded collagenated biphasic calcium phosphate in rabbit sinus. Clinical Implant Dentistry and Related Research 17: 1103-1113.

Kim, J. W., Jung, I. H., Lee, K. I., Jung, U. W., Kim, C. S., Choi, S. H., Cho, K. S. \& Yun, J. H. (2012) Volumetric bone regenerative efficacy of biphasic calcium phosphate-collagen composite block loaded with rhbmp-2 in vertical bone augmentation model of a rabbit calvarium. Journal of biomedical materials research. Part A 100: 3304-3313. 
Kim, S. J., Shin, H. S. \& Shin, S. W. (2010) Effect of bone block graft with rhbmp-2 on vertical bone augmentation. International Journal of Oral and Maxillofacial Surgery 39: 883-888.

Klein, M. \& Al-Nawas, B. (2011) For which clinical indications in dental implantology is the use of bone substitute materials scientifically substantiated? Systematic review, consensus statements and recommendations of the 1st dgi consensus conference in september 2010, aerzen, germany. European Journal of Oral Implantology 4: 11-29.

Lee, E.U., Lim, H.C., Hong, J.Y., Lee, J.S., Jung, U.W. \& Choi, S.H. (2016) Bone regenerative efficacy of biphasic calcium phosphate collagen composite as a carrier of rhBMP-2. Clinical Oral Implants Research Epub ahead of print.

Lee, J. H., Lee, J. S., Baek, W. S., Lim, H. C., Cha, J. K., Choi, S. H. \& Jung, U. W. (2015) Assessment of dehydrothermally cross-linked collagen membrane for guided bone regeneration around peri-implant dehiscence defects: A randomized singleblinded clinical trial. J Periodontal Implant Sci 45: 229-237.

Mir-Mari, J., Wui, H., Jung, R. E., Hammerle, C. H. \& Benic, G. I. (2016) Influence of blinded wound closure on the volume stability of different gbr materials: An in vitro cone-beam computed tomographic examination. Clinical Oral Implants Research 27: 258-265.

Mordenfeld, A., Hallman, M., Johansson, C. B. \& Albrektsson, T. (2010) Histological and histomorphometrical analyses of biopsies harvested 11 years after maxillary sinus floor augmentation with deproteinized bovine and autogenous bone. Clinical Oral Implants Research 21: 961-970.

Nkenke, E., Schultze-Mosgau, S., Radespiel-Troger, M., Kloss, F. \& Neukam, F. W. (2001) Morbidity of harvesting of chin grafts: A prospective study. Clinical Oral Implants Research 12: 495-502.

Reddi, A. H., Wientroub, S. \& Muthukumaran, N. (1987) Biologic principles of bone induction. Orthopedic Clinics of North America 18: 207-212.

Schmitt, C., Lutz, R., Doering, H., Lell, M., Ratky, J. \& Schlegel, K. A. (2013) Biooss(r) blocks combined with bmp-2 and vegf for the regeneration of bony defects and vertical augmentation. Clinical Oral Implants Research 24: 450-460.

Schwarz, F., Ferrari, D., Balic, E., Buser, D., Becker, J. \& Sager, M. (2010) Lateral ridge augmentation using equine- and bovine-derived cancellous bone blocks: A feasibility study in dogs. Clinical Oral Implants Research 21: 904-912.

Schwarz, F., Ferrari, D., Sager, M., Herten, M., Hartig, B. \& Becker, J. (2009) Guided bone regeneration using rhgdf-5- and rhbmp-2-coated natural bone mineral in rat calvarial defects. Clinical Oral Implants Research 20: 1219-1230.

Schwarz, F., Rothamel, D., Herten, M., Ferrari, D., Sager, M. \& Becker, J. (2008) Lateral ridge augmentation using particulated or block bone substitutes biocoated 
with rhgdf-5 and rhbmp-2: An immunohistochemical study in dogs. Clinical Oral Implants Research 19: 642-652.

Schwarz, F., Rothamel, D., Herten, M., Sager, M. \& Becker, J. (2006) Angiogenesis pattern of native and cross-linked collagen membranes: An immunohistochemical study in the rat. Clinical Oral Implants Research 17: 403-409.

Seeherman, H., Wozney, J. \& Li, R. (2002) Bone morphogenetic protein delivery systems. Spine (Phila Pa 1976) 27: S16-23.

Shin, S. Y., Hwang, Y. J., Kim, J. H. \& Seol, Y. J. (2014) Long-term results of new deproteinized bovine bone material in a maxillary sinus graft procedure. J Periodontal Implant Sci 44: 259-264.

Sigurdsson, T. J., Nygaard, L., Tatakis, D. N., Fu, E., Turek, T. J., Jin, L., Wozney, J. M. \& Wikesjo, U. M. (1996) Periodontal repair in dogs: Evaluation of rhbmp-2 carriers. International Journal of Periodontics and Restorative Dentistry 16: 524-537.

Simion, M., Nevins, M., Rocchietta, I., Fontana, F., Maschera, E., Schupbach, P. \& Kim, D. M. (2009) Vertical ridge augmentation using an equine block infused with recombinant human platelet-derived growth factor-bb: A histologic study in a canine model. International Journal of Periodontics and Restorative Dentistry 29: 245-255.

Simion, M., Rocchietta, I., Kim, D., Nevins, M. \& Fiorellini, J. (2006) Vertical ridge augmentation by means of deproteinized bovine bone block and recombinant human platelet-derived growth factor-bb: A histologic study in a dog model. International Journal of Periodontics and Restorative Dentistry 26: 415-423.

Urist, M. R. (1965) Bone: Formation by autoinduction. Science 150: 893-899.

von Arx, T., Hafliger, J. \& Chappuis, V. (2005) Neurosensory disturbances following bone harvesting in the symphysis: A prospective clinical study. Clinical Oral Implants Research 16: 432-439.

Widmark, G., Andersson, B. \& Ivanoff, C. J. (1997) Mandibular bone graft in the anterior maxilla for single-tooth implants. Presentation of surgical method. International Journal of Oral and Maxillofacial Surgery 26: 106-109.

Yon, J., Lee, J. S., Lim, H. C., Kim, M. S., Hong, J. Y., Choi, S. H. \& Jung, U. W. (2015) Pre-clinical evaluation of the osteogenic potential of bone morphogenetic protein-2 loaded onto a particulate porcine bone biomaterial. Journal of Clinical Periodontology 42: 81-88.

Zeltner, M., Fluckiger, L. B., Hammerle, C. H., Husler, J. \& Benic, G. I. (2016) Volumetric analysis of chin and mandibular retromolar region as donor sites for cortico-cancellous bone blocks. Clinical Oral Implants Research 27: 999-1004.

Zhu, S. J., Choi, B. H., Huh, J. Y., Jung, J. H., Kim, B. Y. \& Lee, S. H. (2006) A comparative qualitative histological analysis of tissue-engineered bone using bone marrow mesenchymal stem cells, alveolar bone cells, and periosteal cells. Oral 
Surgery, Oral Medicine, Oral Pathology, Oral Radiology and Endodontics 101: 164169. 
Table 1a

\begin{tabular}{|c|c|c|c|c|c|}
\hline \multirow{2}{*}{$\begin{array}{l}\text { (a) } \\
\text { Parameter }\end{array}$} & \multirow[b]{2}{*}{ Unit } & \multicolumn{4}{|c|}{ Treatment modality } \\
\hline & & $\begin{array}{l}\text { 1. Block } \\
(n=6)\end{array}$ & $\begin{array}{l}\text { 2. Block-BMP2 } \\
(n=6)\end{array}$ & $\begin{array}{l}\text { 3. Block + CM } \\
(n=6)\end{array}$ & $\begin{array}{l}\text { 4. Block + CM- } \\
\text { BMP2 }(n=6)\end{array}$ \\
\hline & & $\begin{array}{l}\text { Mean } \pm \text { SD } \\
\text { (Q1, median, } \\
\text { Q3) }\end{array}$ & & & \\
\hline AA & $\mathrm{mm2}$ & $\begin{array}{l}10.4 \pm 4.2 \\
(6.8,10.1,13.7)\end{array}$ & $\begin{array}{l}11.8 \pm 2.8 \\
(9.2,11.9,14.1)\end{array}$ & $\begin{array}{l}9.8 \pm 2.9 \\
(7.7,10.4,12.0)\end{array}$ & $\begin{array}{l}8.5 \pm 2.2 \\
(6.6,8.0,10.4)\end{array}$ \\
\hline NB & $\mathrm{mm} 2$ & $\begin{array}{l}2.2 \pm 1.3 \\
(1.1,2.0,3.2)\end{array}$ & $\begin{array}{l}2.0 \pm 0.5 \\
(1.6,2.1,2.4)\end{array}$ & $\begin{array}{l}2.7 \pm 1.2 \\
(1.6,2.7,4.0)\end{array}$ & $\begin{array}{l}1.8 \pm 0.7 \\
(1.3,1.8,2.4)\end{array}$ \\
\hline NB & $\%$ & $\begin{array}{l}20.8 \pm 5.9 \\
(14.1,21.6,26.0)\end{array}$ & $\begin{array}{l}17.2 \pm 3.7 \\
(14.4,15.5,21.7)\end{array}$ & $\begin{array}{l}26.7 \pm 8.0 \\
(17.1,30.2,32.6)\end{array}$ & $\begin{array}{l}21.3 \pm 5.4 \\
(16.0,22.5,25.5)\end{array}$ \\
\hline BS & $\mathrm{mm} 2$ & $\begin{array}{l}3.7 \pm 1.0 \\
(2.9,3.5,4.2)\end{array}$ & $\begin{array}{l}6.1 \pm 2.2 \\
(4.1,5.4,8.7)\end{array}$ & $\begin{array}{l}3.4 \pm 1.0 \\
(2.5,3.4,4.2)\end{array}$ & $\begin{array}{l}3.4 \pm 1.2 \\
(2.6,3.2,3.9)\end{array}$ \\
\hline BS & $\%$ & $\begin{array}{l}37.7 \pm 9.8 \\
(29.7,33.5,49.7)\end{array}$ & $\begin{array}{l}50.8 \pm 9.4 \\
(40.8,52.6,58.0)\end{array}$ & $\begin{array}{l}36.3 \pm 8.1 \\
(28.9,33.8,44.8)\end{array}$ & $\begin{array}{l}40.5 \pm 12.7 \\
(27.4,39.5,53.9)\end{array}$ \\
\hline NMT & $\mathrm{mm} 2$ & $\begin{array}{l}4.5 \pm 2.3 \\
(2.4,4.8,6.5)\end{array}$ & $\begin{array}{l}3.7 \pm 0.9 \\
(2.7,3.8,4.6)\end{array}$ & $\begin{array}{l}3.6 \pm 1.2 \\
(2.9,3.6,4.8)\end{array}$ & $\begin{array}{l}3.3 \pm 2.0 \\
(1.6,2.9,4.8)\end{array}$ \\
\hline NMT & $\%$ & $\begin{array}{l}41.5 \pm 10.5 \\
(34.4,39.7,51.2)\end{array}$ & $\begin{array}{l}32.0 \pm 6.8 \\
(27.1,32.8,37.4)\end{array}$ & $\begin{array}{l}37.0 \pm 3.4 \\
(33.4,37.7,40.0)\end{array}$ & $\begin{array}{l}38.2 \pm 17.4 \\
(22.3,36.8,56.6)\end{array}$ \\
\hline DEF-fBIC & $\mathrm{mm}$ & $\begin{array}{l}3.0 \pm 0.6 \\
(2.4,3.0,3.7)\end{array}$ & $\begin{array}{l}2.7 \pm 0.9 \\
(2.1,2.6,3.4)\end{array}$ & $\begin{array}{l}3.0 \pm 0.9 \\
(2.1,3.3,3.6)\end{array}$ & $\begin{array}{l}2.3 \pm 0.9 \\
(1.4,2.4,3.2)\end{array}$ \\
\hline DEF-NB & $\mathrm{mm}$ & $\begin{array}{l}4.4 \pm 0.6 \\
(4.0,4.3,4.8)\end{array}$ & $\begin{array}{l}4.1 \pm 1.0 \\
(3.4,4.5,4.9)\end{array}$ & $\begin{array}{l}3.9 \pm 0.8 \\
(3.2,4.0,4.6)\end{array}$ & $\begin{array}{l}3.4 \pm 1.1 \\
(2.1,3.8,4.3)\end{array}$ \\
\hline DEF-BS & $\mathrm{mm}$ & $\begin{array}{l}4.8 \pm 0.5 \\
(4.4,4.8,5.2)\end{array}$ & $\begin{array}{l}4.9 \pm 0.3 \\
(4.5,4.9,5.2)\end{array}$ & $\begin{array}{l}4.6 \pm 0.7 \\
(3.8,4.7,5.2)\end{array}$ & $\begin{array}{l}4.2 \pm 0.7 \\
(3.8,4.5,4.6)\end{array}$ \\
\hline I-NB & $\mathrm{mm}$ & $\begin{array}{l}2.3 \pm 1.0 \\
(1.4,2.2,3.1)\end{array}$ & $\begin{array}{l}2.5 \pm 0.7 \\
(2.0,2.4,3.0)\end{array}$ & $\begin{array}{l}2.2 \pm 0.8 \\
(1.6,2.3,2.8)\end{array}$ & $\begin{array}{l}2.1 \pm 0.6 \\
(1.4,2.3,2.5)\end{array}$ \\
\hline I-BS & $\mathrm{mm}$ & $\begin{array}{l}2.6 \pm 1.0 \\
(1.7,2.6,3.4)\end{array}$ & $\begin{array}{l}2.8 \pm 0.6 \\
(2.4,2.8,3.2)\end{array}$ & $\begin{array}{l}2.6 \pm 0.9 \\
(1.9,2.6,3.3)\end{array}$ & $\begin{array}{l}2.6 \pm 0.5 \\
(2.2,2.8,3.0)\end{array}$ \\
\hline
\end{tabular}


Table 1b

\begin{tabular}{|c|c|c|c|c|c|c|}
\hline (b) & Statisti & halysis* & & & & \\
\hline Parameter & 1 v.s 2 & 1 vs. 3 & 1 vs. 4 & 2 vs. 3 & 2 vs. 4 & 3 vs. 4 \\
\hline AA & 0.563 & 0.844 & 0.313 & 0.156 & $0.031 \dagger$ & 0.219 \\
\hline NB & 0.840 & 0.560 & 0.310 & 0.160 & 1.000 & 0.160 \\
\hline NB (\%) & 0.156 & 0.094 & 0.438 & 0.068 & 0.068 & 0.313 \\
\hline BS & 0.094 & 1.000 & 0.688 & $0.031 \dagger$ & 0.156 & 1.000 \\
\hline BS (\%) & $0.031 \dagger$ & 0.313 & 1.000 & $0.031 \dagger$ & 0.219 & 0.688 \\
\hline NMT & 0.310 & 0.560 & 0.160 & 1.000 & 0.310 & 0.840 \\
\hline NMT (\%) & 0.160 & 0.440 & 0.840 & 0.310 & 0.560 & 1.000 \\
\hline DEF-fBIC & 0.563 & 1.000 & 0.094 & 0.438 & 0.688 & 0.156 \\
\hline DEF-NB & 0.560 & 0.160 & 0.160 & 1.000 & 0.440 & 0.690 \\
\hline DEF-BS & 0.590 & 1.000 & 0.219 & 1.000 & 0.063 & 0.438 \\
\hline I-NB & 0.440 & 0.690 & 0.440 & 0.310 & 0.160 & 1.000 \\
\hline I-BS & 0.690 & 0.840 & 0.690 & 0.690 & 0.560 & 1.000 \\
\hline $\begin{array}{l}\text { AA, augmer } \\
\text { non-minera } \\
\text { bone defect } \\
\text { distance be } \\
\text { DEF-BS, ap } \\
\text { coronal leve } \\
\text { the most bu } \\
\text { and the mo } \\
{ }^{*} \text {, results of }\end{array}$ & $\begin{array}{l}\text { co-corona } \\
\text { of bone } \\
\text { cal aspec } \\
\text { buccal a } \\
\text { epeated }\end{array}$ & $\begin{array}{l}\text { oronal le } \\
\text { Il margin } \\
\text { ance bet } \\
\text { itute; I-N } \\
\text { lew bone } \\
\text { of new } \\
\text { xon signe }\end{array}$ & $\begin{array}{l}\text { the apic } \\
\text { icco-oral } \\
\text {; bucco- } \\
\text { SD, star } \\
\text { k test; } \dagger\end{array}$ & $\begin{array}{l}\text { defect an } \\
\text { argin of th } \\
\text { ince betw } \\
\text { distance b } \\
\text { deviation } \\
\text { tistically si }\end{array}$ & $\begin{array}{l}\text { ant; DEF } \\
\text { most coro } \\
\text { er bone } d \\
\text { e buccal } \\
\text { n the buc } \\
\text { first quarti } \\
\text { int }\end{array}$ & $\begin{array}{l}\text { titute; NMT, } \\
\text { f the former } \\
\text { pico-coronal } \\
\text { el of new bone; } \\
\text { and the most } \\
\text { surface and } \\
\text { plant surface } \\
\text {, third quartile; }\end{array}$ \\
\hline
\end{tabular}




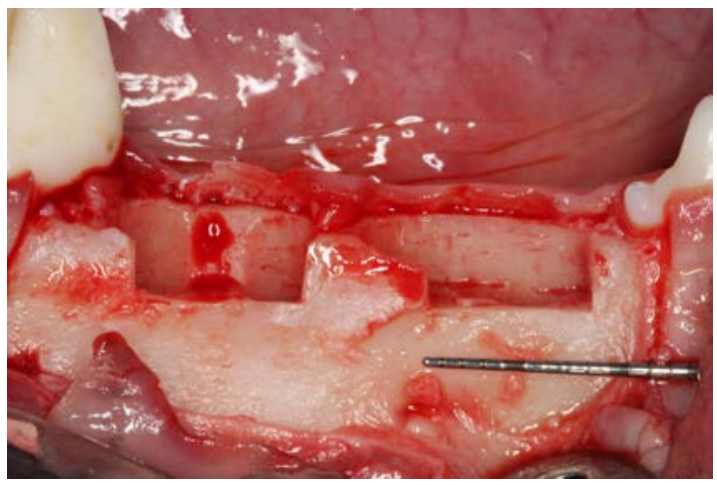

Figure 1a

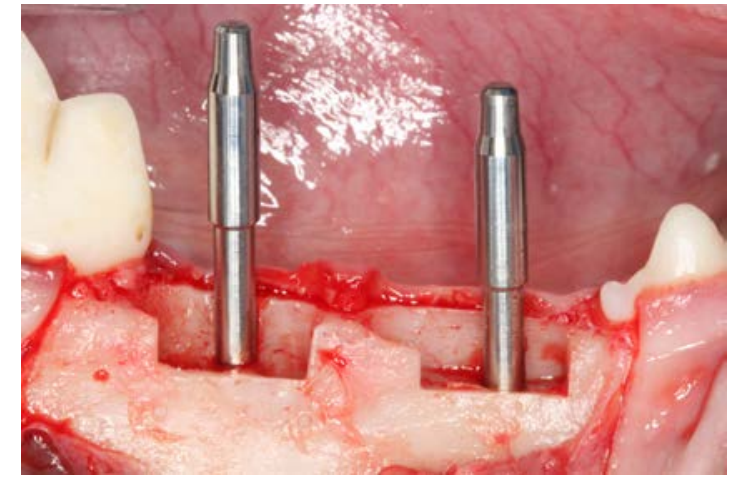

Figure 1b

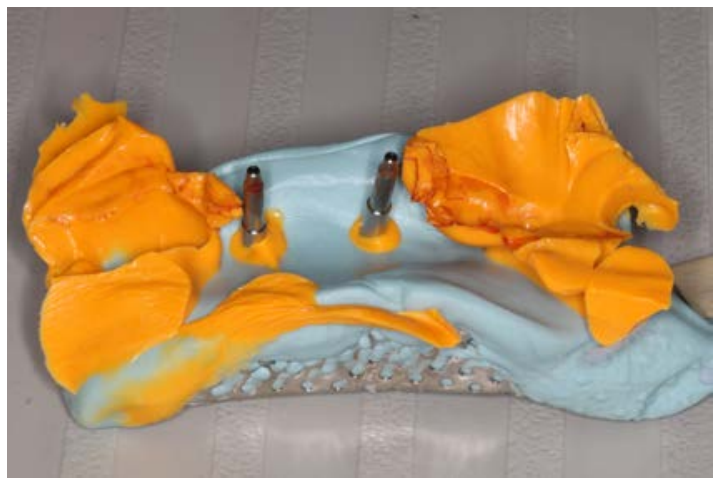

Figure 1c

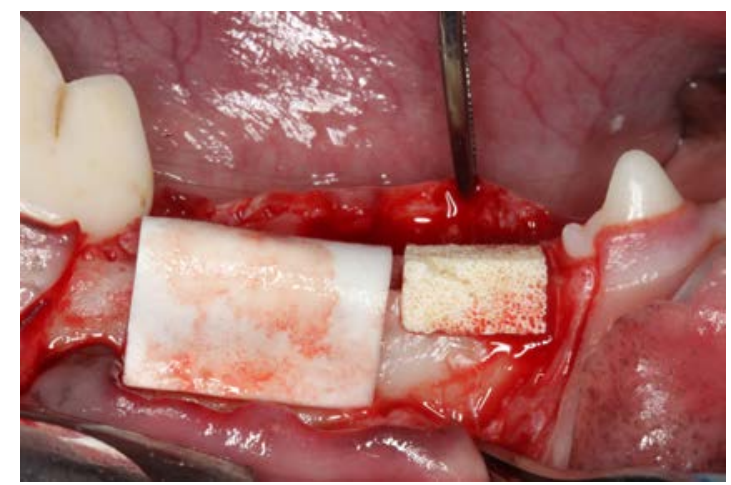

Figure 1d 


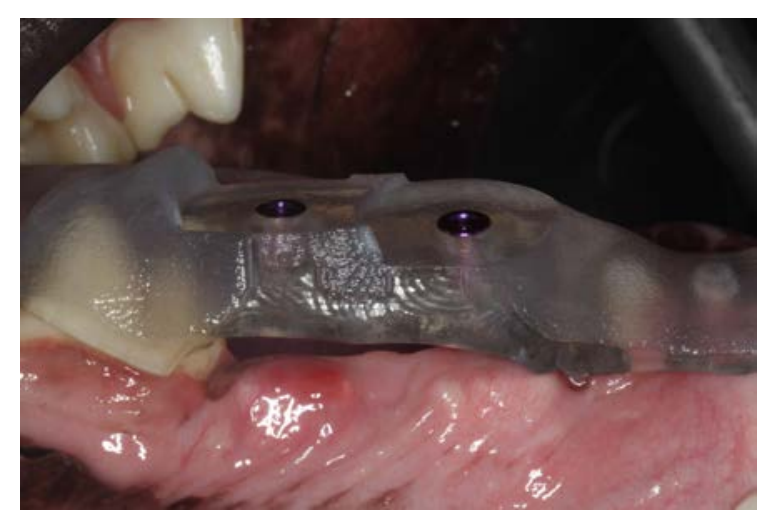

Figure 2a

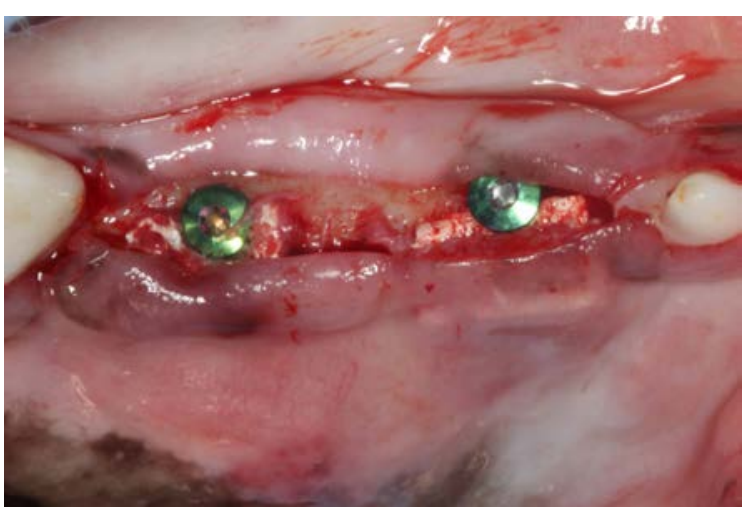

Figure $2 b$

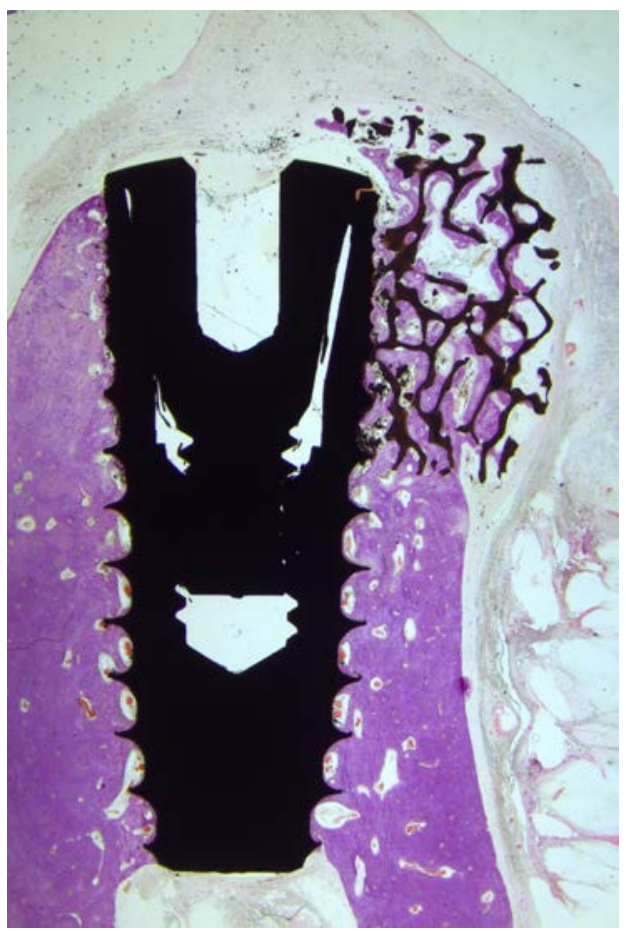

Figure $3 a$ 


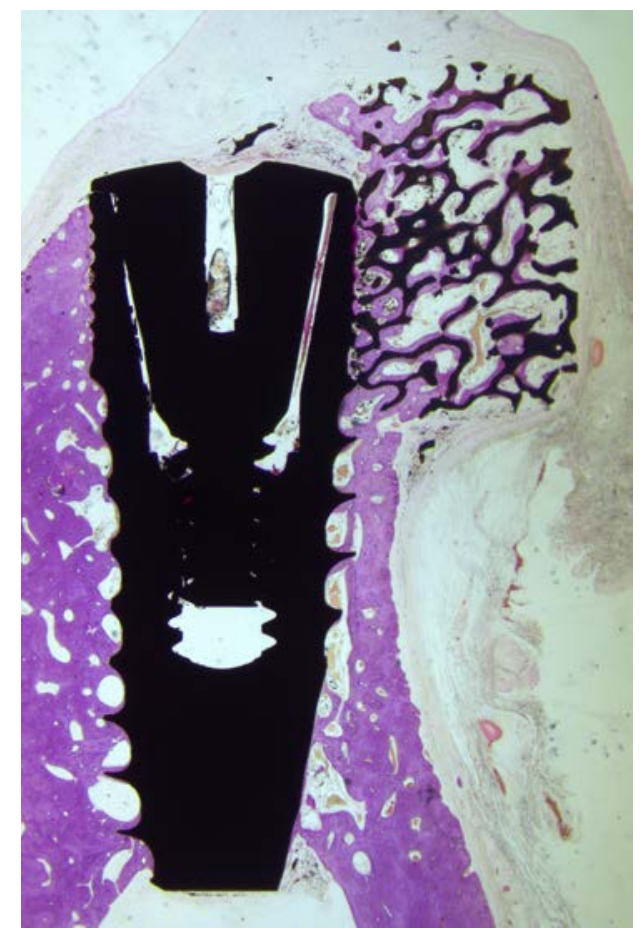

Figure $3 b$

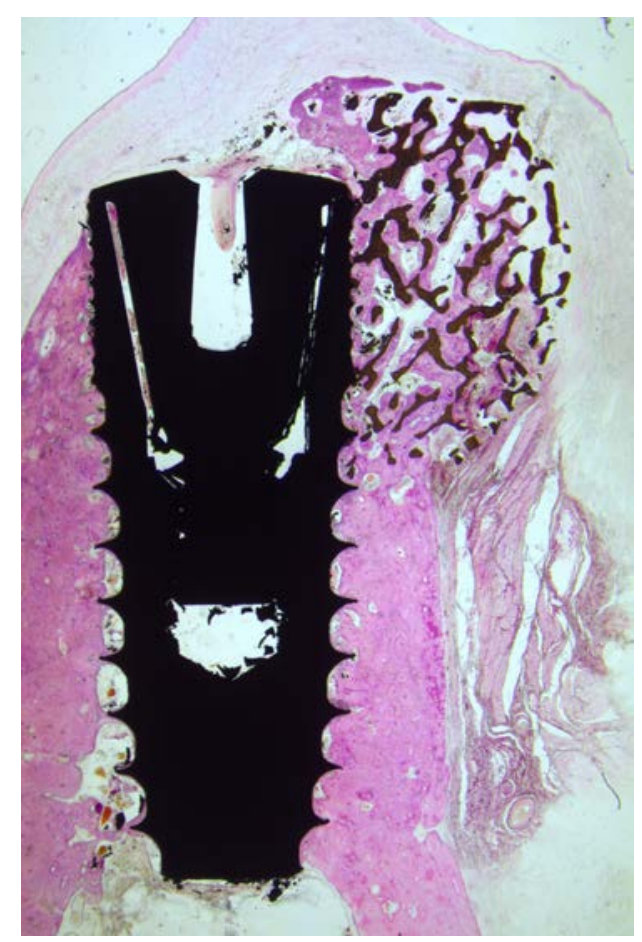

Figure $3 c$ 


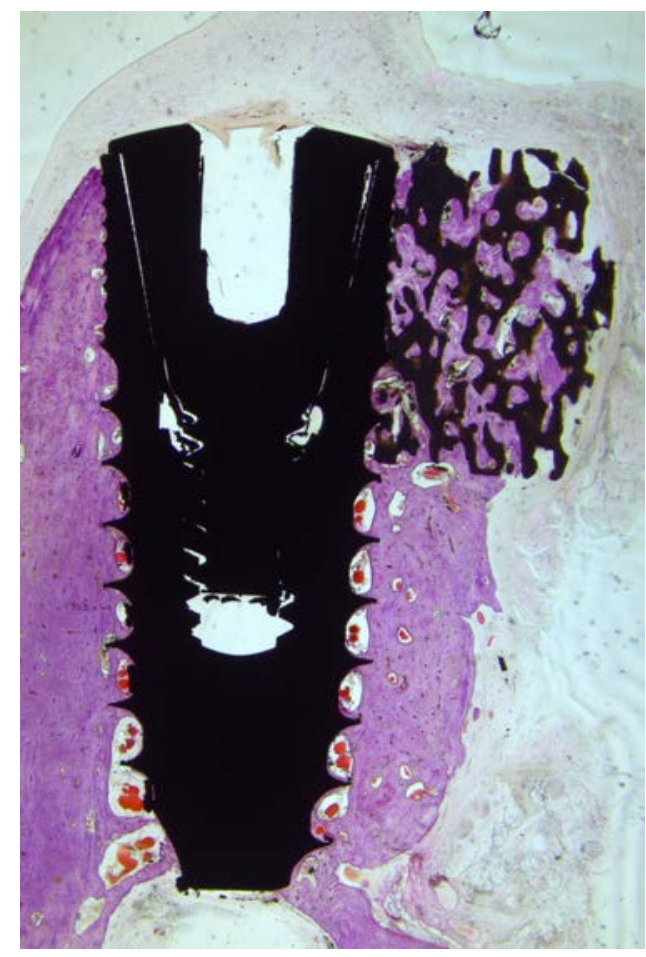

Figure 3d

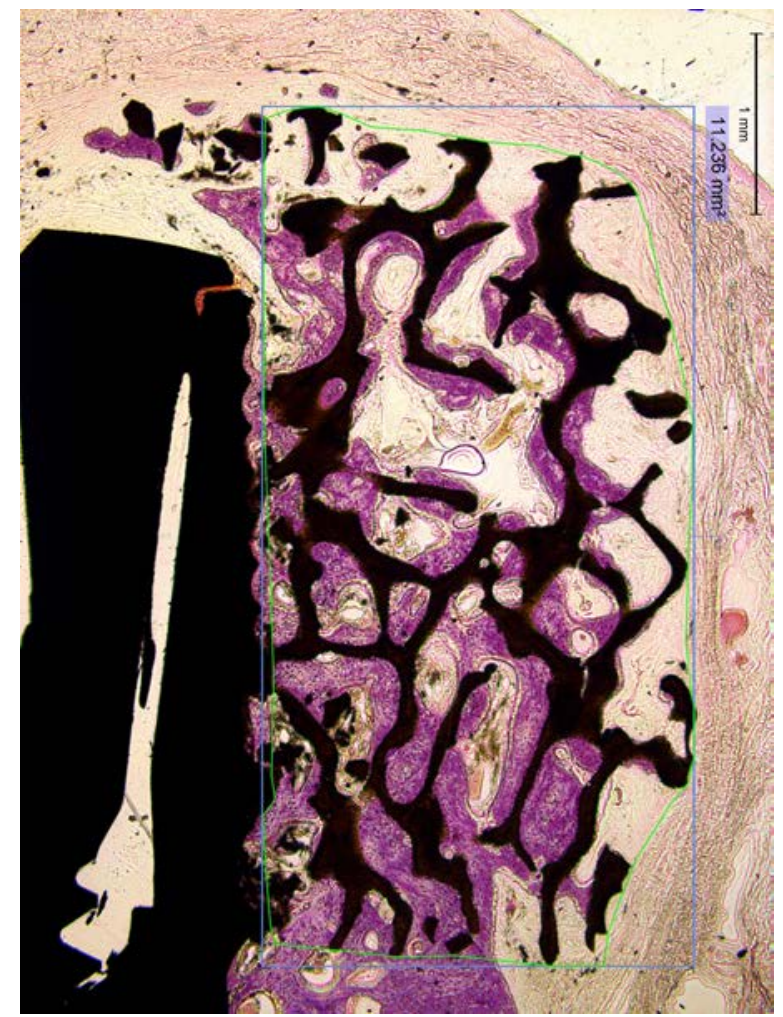

Figure $4 a$ 


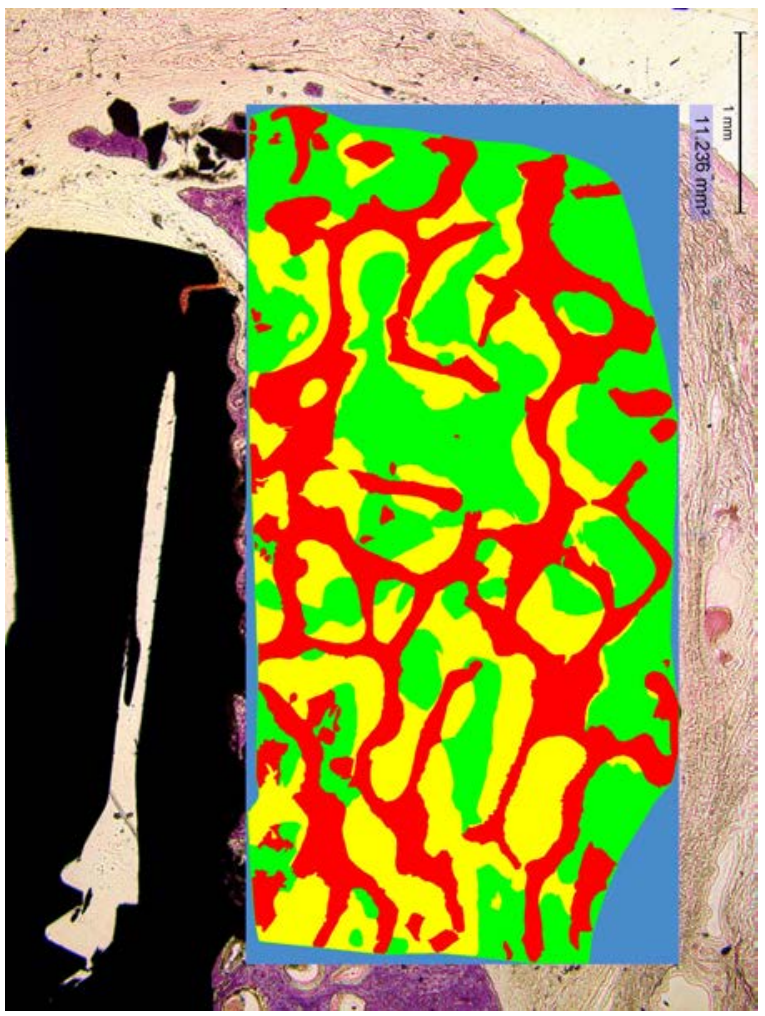

Figure 4b

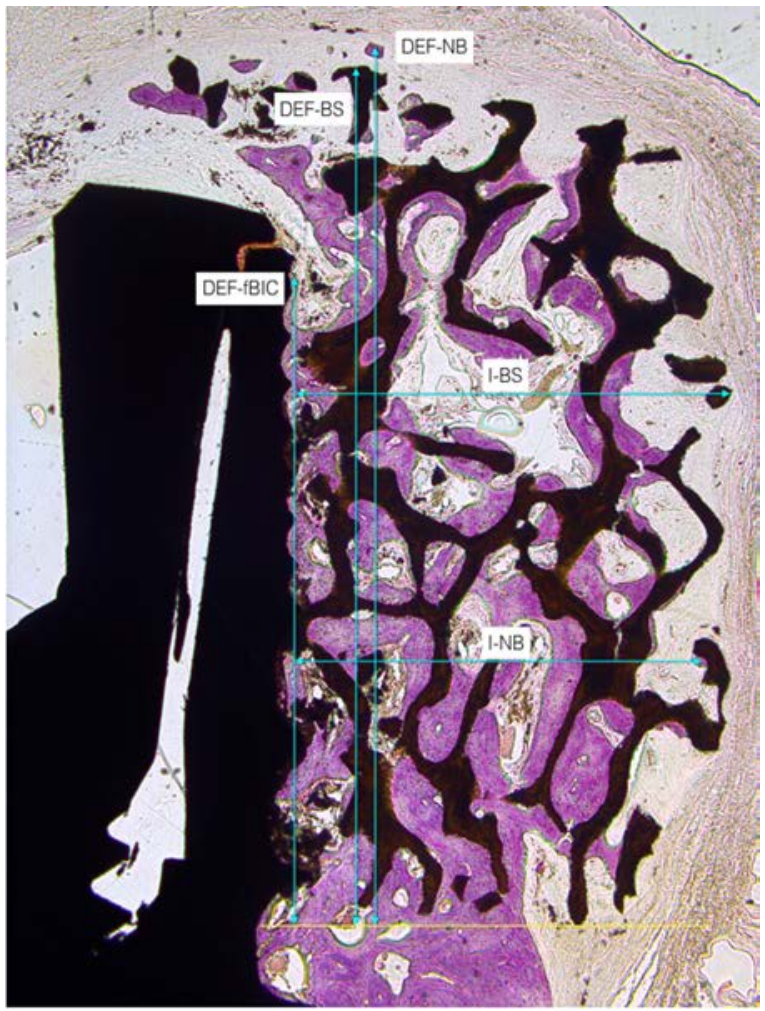

Figure 5 


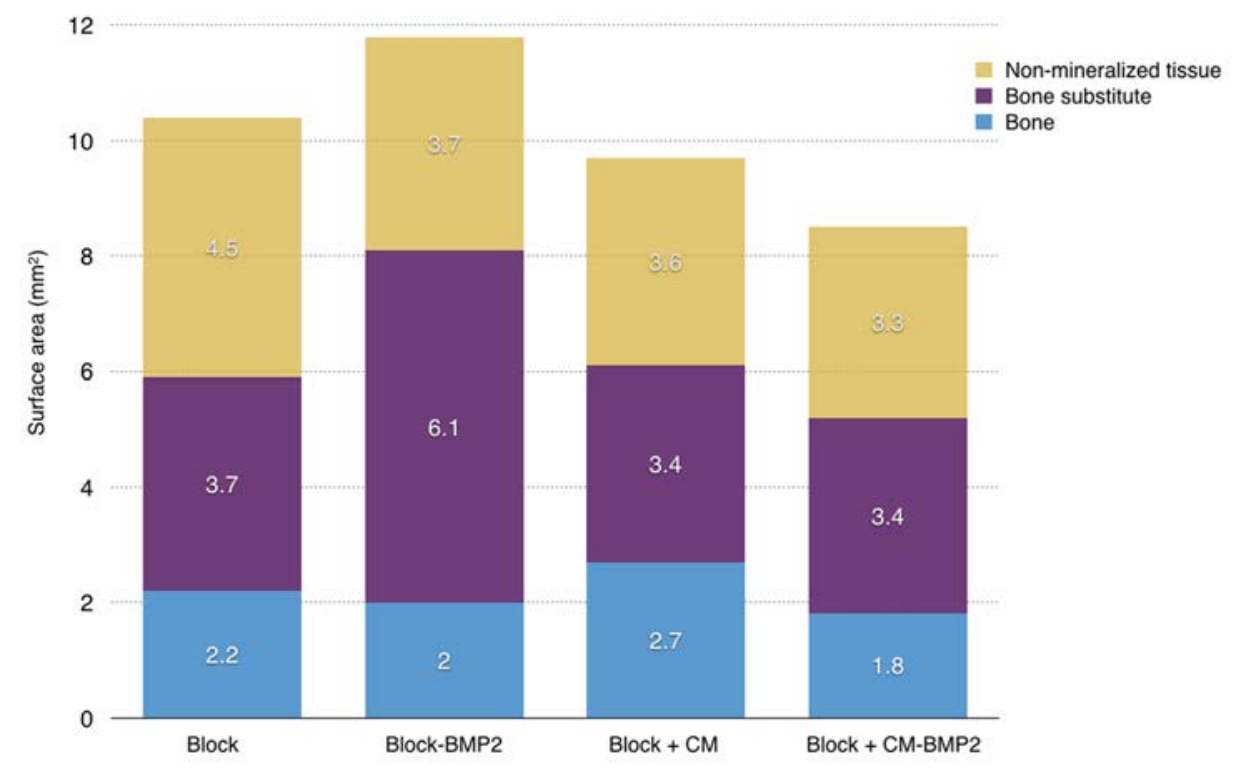

Figure 6a

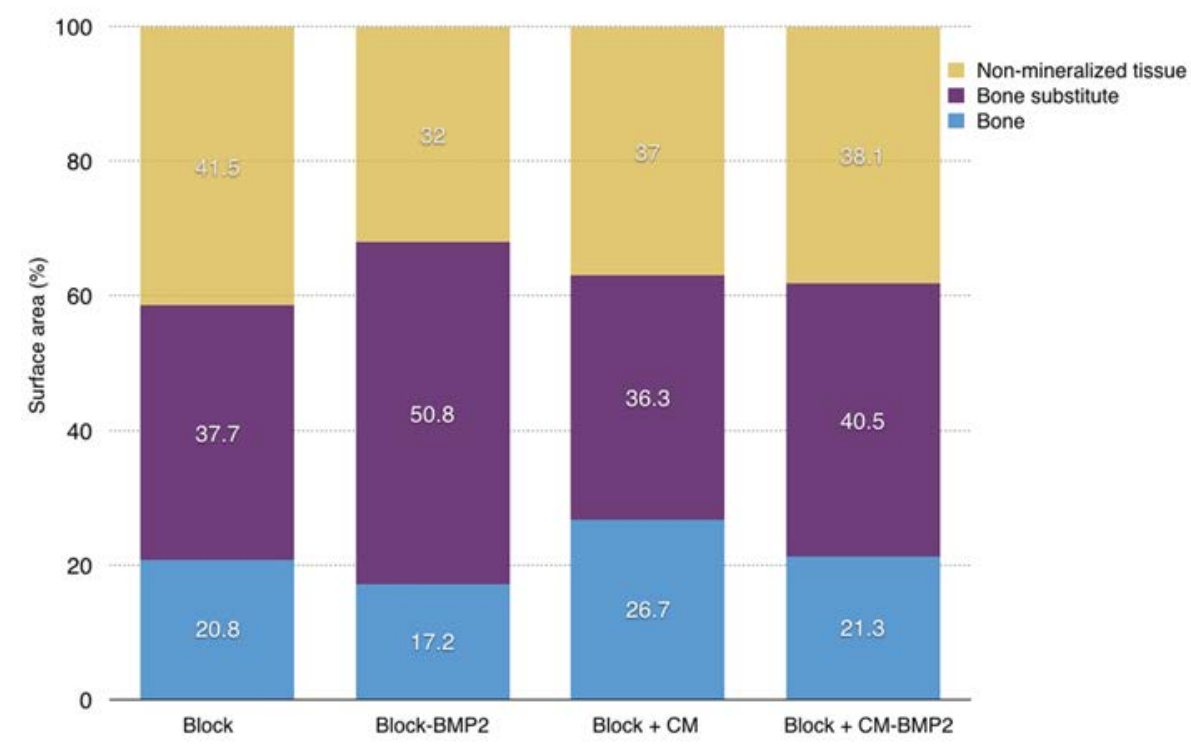

Figure $6 b$ 